\title{
Reinforcement of reproductive isolation between adjacent populations in the Park Grass Experiment
}

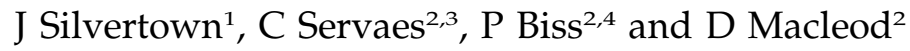 \\ ${ }^{1}$ Department of Biological Sciences, Ecology and Evolution Research Group, The Open University, Walton Hall, Milton Keynes MK7 \\ 6AA, UK; ${ }^{2}$ Rothamsted Research, Harpenden, Hertfordshire AL5 2JQ, UK
}

\begin{abstract}
It has been debated, ever since Charles Darwin and Alfred Russell Wallace disagreed about the matter, whether natural selection plays a role in reinforcing reproductive isolation during the earliest stages of speciation. Recent theory suggests that it can do so, but until now the empirical evidence has conspicuously lacked a case in which reinforcement has actually been observed to split a population. We show that this has occurred at least once in
\end{abstract}

populations of the grass Anthoxanthum odoratum growing in the Park Grass Experiment where flowering time has shifted at the boundaries between plots. As a consequence, gene flow via pollen has been severely limited and adjacent populations that had a common origin at the start of the experiment in 1856 have now diverged at neutral marker loci. Heredity (2005) 95, 198-205. doi:10.1038/sj.hdy.6800710; published online 6 July 2005

Keywords: Anthoxanthum odoratum; $F_{\text {st }}$; flowering phenology; gene flow; reinforcement; sympatric speciation

\section{Introduction}

In the Origin of Species, Charles Darwin (1859) explained at length how adaptation evolves through natural selection, but he had much less to say about the very subject of his title - how new species are formed. It is self-evident that speciation requires incipient species to become reproductively isolated from their progenitors, but precisely how this happens is not obvious. Isolation can occur through mechanisms such as geographic separation or spontaneous changes in ploidy (Levin, 2002) and need not involve natural selection for reproductive isolation. What role, if any, natural selection itself plays in reproductive isolation in the earliest stages of speciation when populations first begin to diverge has been a contentious issue since the late 19th century when Alfred Russell Wallace (1889) advocated the idea that the low fitness of hybrids should select for reproductive isolation between diverging populations. This selective mechanism has been called the Wallace effect or (more frequently) reinforcement.

Support for reinforcement waxed and waned throughout the 20th century, enjoying increasing popularity after Dobzhansky elaborated the theory in the 1940s, going out of favor in the 1980s when theory discounted it, only to recover more recently when new theoretical models turned in its favour (Noor, 1999). Prezygotic isolating mechanisms have now been investigated in over 100 mathematical models, firmly establishing a theoretical

Correspondence: J Silvertown, Ecology and Evolution Research Group, Department of Biological Sciences, The Open University, Walton Hall, Milton Keynes MK7 6AA, UK. E-mail: j.silvertown@open.ac.uk

${ }^{3}$ Current address: National Botanic Garden of Belgium, Meise, Belgium ${ }^{4}$ Current address: Ecology and Evolution Research Group, Departmetn of Biological Sciences, The Open University, Milton Keynes, UK

Received 18 November 2004; accepted 31 May 2005; published online 6 July 2005 basis for the evolution of reinforcement under the right conditions (Kirkpatrick and Ravigne, 2002; Servedio and Noor, 2003; Servedio, 2004).

Empirical evidence of reinforcement has rarely been complete enough in any one case to exclude alternative interpretation (Butlin, 1987), although recent studies of flycatchers (Saetre et al, 1997), salmon (Hendry et al, 2000) and insects (Higgie et al, 2000; Nosil et al, 2003) have come down more conclusively in its favor. However, even these studies fall short of showing that a single ancestral population was split by the evolution of premating reproductive isolation in situ. Indeed, it has been said that such evidence might even be almost impossible to obtain because the history of populations is usually not known (Barton, 2000). In this paper, we revisit a study system in which population history is known and for which preliminary evidence of reinforcement was reported in the 1970s (Snaydon and Davies, 1976). Using molecular genetic markers and additional field sampling, we show that reinforcement has contributed to reproductive isolation in at least one population.

The study system in question is the Park Grass Experiment (PGE) at Rothamsted Experimental Station in Harpenden, England. The PGE is the world's longestrunning ecological experiment and was begun in 1856 when a meadow of uniform vegetation composition was divided into plots that were then given different fertilizer treatments. Most of these treatments continue to the present day, although with some subdivision of plots to allow additional treatments to be applied. There are no guard areas between treatments and the boundaries between plots receiving different fertilizers remain sharp and highly visible because of differences in the height and composition of the vegetation (Kunin, 1998).

Snaydon and Davies studied the short-lived perennial grass Anthoxanthum odoratum at Park Grass in the 
1960-1970s and found experimental evidence of local adaptation in many traits, including disease resistance, plant height and tolerance of $\mathrm{pH}$ and $\mathrm{Al}$ (Snaydon, 1970; Snaydon and Davies, 1972; Davies and Snaydon, 1973a, b, 1974). Reciprocal transplants between plots showed that selection against transplanted genotypes originating from a plot with a different treatment could be as high as $70 \%$ in a single season (Davies and Snaydon, 1976). Since A. odoratum is wind pollinated and outcrossing ( $t=0.970 \pm 0.057$; Silvertown et al, 2002), pollen flow between adjacent plots certainly occurs, suggesting that local adaptation in the PGE must happen in the face of gene flow from nearby, nonadapted populations. This ought to impede the rapid evolution of local adaptation, but it has apparently not prevented it since Snaydon and Davies (1982) found differences between adjacent populations that had experienced different liming treatments for as few as 6 years.

Premating reproductive barriers between plots could potentially explain how rapid evolutionary divergence between PGE populations has been possible. Accordingly, Snaydon and Davies (1976) recorded the flowering phenology of $A$. odoratum along transects crossing certain plot boundaries. They found that plants sampled from an area straddling the boundaries between plots flowered 4-6 days earlier than the populations on either side, forming inverse clines at the borders of several plots. Phenological differences between plants from the border and interior of PGE plots persisted when Snaydon and Davies (1976) raised them from tillers or seed in a common environment. This suggested that the phenological differences were genetic, although whether they had been selected for because of an advantage due to reproductive isolation or were the consequence of selection caused by ecological conditions in the border zone was not clear. A simulation model by Caisse and Antonovics (1978) showed that an inverse cline is a signature of reinforcement, so long as direct causes of a shift in flowering time at the border can be ruled out. In a similar model, Van Dijk and Bijlsma (1994) found that the cline shifted from inverse to monotonic after 200 generations. The generation time of $A$. odoratum at Park Grass is at least 2 years, so no populations at plot boundaries can have been separated for more than about 70 generations.
Two important questions about reproductive isolation at Park Grass remain to be answered before it can be concluded that reinforcement has occurred there. First is whether ecological conditions at plot borders are different in some way that might select for shifted phenology, for example, if boundaries are repeatedly trampled by being used for access; and second is whether differences in flowering time have been sufficient to form a reproductive barrier that limits gene flow via pollen between adjacent populations of $A$. odoratum. Both are addressed here.

\section{Methods}

\section{Park Grass plots studied}

We sampled the seven plot borders listed in Table 1, including one boundary between two control plots (Plots 2 and 3). Any phenological difference at the boundary between control plots would implicate some artefactual effect or direct selection on flowering time rather than selection for reproductive isolation because neither side of the boundary has received any fertilizer treatment or liming since 1864 and there is no difference in soil $\mathrm{pH}$ between them. Snaydon and Davies (1976) recorded flowering phenology in $A$. odoratum across the boundary between the limed (L) subplots of Plots 8 and 9 and the boundary between the limed (L) and unlimed (U) halves of Plot 1 . The 1L/1U boundary could not be included in the present study because the internal borders within plots are now demarcated by a strip that is regularly mown. External borders between different plots are not mown in this way, but plots have been further subdivided for liming since 1968 and four subplots are now labelled (a)-(d), where (a) receives the most lime and (d) none. Our phenological measurements were made on the unlimed (d) subplots because these have the longest histories of continuous treatment and because $A$. odoratum is more abundant on these subplots than on limed ones, thus giving us maximum sample sizes.

\section{Flowering phenology}

Five replicate belt transects, $4 \mathrm{~m}$ in length and $1 \mathrm{~m}$ wide, were placed at equally spaced intervals across each of the seven boundaries. Transects lay perpendicular to each

Table 1 Details of the Park Grass plots and their fertilizer treatments included in the study of flowering phenology

\begin{tabular}{|c|c|c|c|c|c|c|c|}
\hline \multirow[t]{2}{*}{ Plot } & \multirow[t]{2}{*}{ Date treatment initiated } & \multirow[t]{2}{*}{ Genetic markers } & \multicolumn{5}{|c|}{ Fertilizer treatments $(\mathrm{kg} / \mathrm{ha} /$ year $)$} \\
\hline & & & $N$ & $P$ & $K$ & Other & $p H$ \\
\hline $2-2$ & 1863 & & Nil & Nil & Nil & Nil & 5.2 \\
\hline 3 & 1856 & & Nil & Nil & Nil & Nil & 5.2 \\
\hline 8 & 1863 & $\mathrm{nr}, \mathrm{cp}$ & Nil & Nil & Nil & $\mathrm{Na}, \mathrm{Mg}$ & 5.2 \\
\hline $9-1$ & 1989 & $\mathrm{nr}, \mathrm{cp}$ & Nil & 35 & 225 & $\mathrm{Na}, \mathrm{Mg}$ & 3.9 \\
\hline $9-2$ & 1856 & & $96^{a}$ & 35 & 225 & $\mathrm{Na}, \mathrm{Mg}$ & 3.6 \\
\hline $11-2$ & 1883 & $\mathrm{nr}$ & $144^{\mathrm{a}}$ & 35 & 225 & $\mathrm{Na}, \mathrm{Mg}, \mathrm{Si}$ & 3.7 \\
\hline 12 & 1856 & $\mathrm{nr}, \mathrm{cp}$ & Nil & Nil & Nil & Nil & 5.2 \\
\hline $14-1$ & 1989 & & Nil & 35 & 225 & $\mathrm{Na}, \mathrm{Mg}$ & 5.6 \\
\hline $14-2$ & 1858 & & $96^{a}$ & 35 & 225 & $\mathrm{Na}, \mathrm{Mg}$ & 6.1 \\
\hline 15 & 1876 & & Nil & 35 & 225 & $\mathrm{Na}, \mathrm{Mg}$ & 4.9 \\
\hline 16 & 1858 & & 48 & 35 & 225 & $\mathrm{Na}, \mathrm{Mg}$ & 5.3 \\
\hline
\end{tabular}

Only unlimed, d-subplots of these plots were sampled. Nuclear (nr) and chloroplast (cp) genetic markers were scored for the populations as shown.

${ }^{\text {aN }}$ applied as ammonium sulphate. 


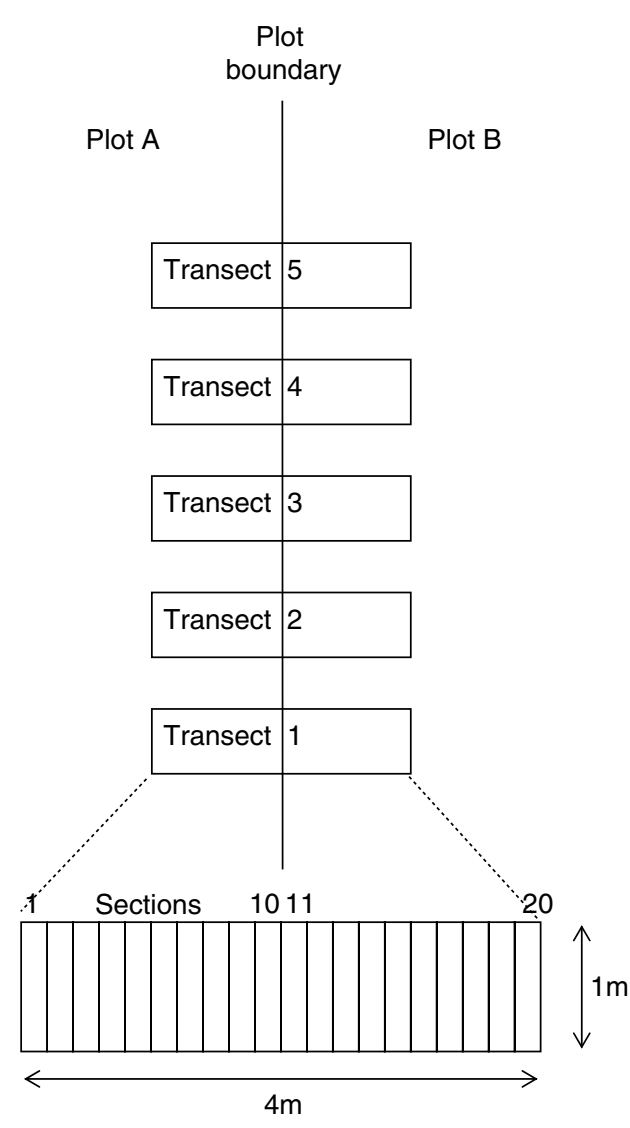

Figure 1 Layout of the sampling scheme for phenological recording. 'Plot $\mathrm{A}^{\prime}$ and 'Plot B' signify any two adjacent plots.

boundary and were intersected by the boundary at their mid-point. Each 4-metre transect was divided along its length into twenty $20 \mathrm{~cm}$ sections, 10 sections lying either side of the boundary (Figure 1). The phenological stage of all A. odoratum inflorescences present (to a maximum of 50 per section) in each $20 \mathrm{~cm}$ transect section was recorded between 15 and 22 May 2001, with all sampling for each pair of plots completed within the same day. The precise number of genets sampled is not known, but it would have been approximately equal to the number of inflorescences, which varied. Each inflorescence sampled was given a phenological score on a six-point scale as follows: $1=$ inflorescence with no anthesis; $2=$ anthesis in $\frac{1}{4}$ of the inflorescence; $3=$ anthesis in $\frac{1}{2}$ of the inflorescence; $4=$ anthesis in $\frac{3}{4}$ of the inflorescence; $5=$ anthesis in the final $\frac{1}{4}$ of the inflorescence; $6=$ anthesis and flowering completed. It took about 20 days for populations on most plots to progress from an average phenological score of zero to an average score of 6 .

Each pair of plots was separately analysed by an ANOVA of split plot design with five replicate transects (Blocks), each containing two plots split into 10 Sections (numbers 1-10 and 11-20) parallel to the border. The response variate was the mean phenological score per $20 \mathrm{~cm}$ Section of each transect. As seven ANOVAs were used, the value of $\alpha$ employed to judge the significance of the 21 resulting $P$-values was adjusted to allow for multiple comparisons using the step-up method of the false discovery rate (FDR) procedure (Benjamini and
Hochberg, 1995). Where the data indicated an inverse cline might be present, scores for individual plants were compared between adjacent sections by a univariate planned comparison $t$-test.

\section{Gene flow}

The ratio of gene flow via pollen and seeds across the Plot $8 / 9$ boundary, where flowering time showed an inverse cline, was measured using the formula of Ennos (1994), which is based upon relative estimates of population differentiation $\left(F_{\mathrm{st}}\right)$ derived from the maternally inherited chloroplast (cp) genome, which is transmitted only via seeds and the bi-parentally inherited nuclear (nr) genome, which is transmitted via pollen and seeds:

$$
\frac{\text { gene flow viapollen }}{\text { gene flow via seeds }}=\frac{\left(1 / F_{\mathrm{st}(\mathrm{nr})}-1\right)\left(1 / F_{\mathrm{st}(\mathrm{cp})}-1\right)}{1 / F_{\mathrm{st}(\mathrm{cp})}-1}
$$

This ratio is inversely correlated with reproductive isolation by flowering time because this is a prezygotic mechanism, which restricts gene flow via pollen (the numerator) but not via zygotes (seeds; the denominator). Values of the pollen-to-seed migration ratio at the geographical scale are normally 10 or greater (Petit et al, 2005).

To estimate $F_{\text {st(cp), we used three polymorphic cp }}$ microsatellite markers (WCt5, atpB/rbcL and rpoC2/ rps2; Ishii and McCouch, 2000; Provan et al, 2004) to haplotype a total of 55 Anthoxanthum plants sampled from either ends of the transect crossing the 8/9-1 boundary and from control (unfertilized) Plot 12. PCR was carried out in $20 \mu \mathrm{l}$ reactions containing 1-2 $\mu \mathrm{l}$ template DNA, 5 pmol of each primer, $200 \mu \mathrm{M}$ of each dNTP, standard buffer (supplied with the Taq) containing $1.5 \mathrm{mM} \mathrm{MgCl} 2$ and $1 \mathrm{U}$ of Taq DNA polymerase in a Techne Genius thermal cycler using the following profile: initial denaturation for $4 \mathrm{~min}$ at $94^{\circ} \mathrm{C}$, followed by 35 cycles of $94^{\circ} \mathrm{C}$ for $1 \mathrm{~min}, 55^{\circ} \mathrm{C}$ for $1 \mathrm{~min}, 72^{\circ} \mathrm{C}$ for $2 \mathrm{~min}$ and a final extension for $5 \mathrm{~min}$ at $72^{\circ} \mathrm{C}$. Any samples that did not amplify with this regime were repeated using extra $\mathrm{MgCl}_{2}$ to bring the final concentration to $2 \mathrm{mM}$. Fluorescent (IR800)-labelled forward primers were used for the analysis. PCR products were visualized on a Licor Gene ReadIR 4200 sequencer and analysed using Gene ImagIR software. $F_{\text {st }}$ for cp loci was analysed using the program GDA (Lewis and Zaykin, 2002) set for haploid data.

We used inter-simple-sequence repeat (ISSR) markers (Zietkiewicz et al, 1994) to estimate $F_{\text {st(nr) }}$. These markers were chosen because the development time was short and they were known to be highly polymorphic. ISSRs markers are dominant, but this was not considered a disadvantage in this study because $A$. odoratum is tetraploid. Unless allele dosage can be determined, codominant markers give no more information for a polyploid than do dominant DNA markers. Nine ISSR loci were scored in each of a total of 113 plants of Anthoxanthum sampled at either end and in the middle of transects crossing the boundaries of Plots 8/9-1 and $11-2 / 12$. Leaf tissue samples were snap-frozen in liquid nitrogen in the field and stored at $-80^{\circ} \mathrm{C}$. DNA was extracted using Biorad and DNeasy plant isolation kits and quantified on a $0.8 \%$ agarose gel containing $3 \mu \mathrm{l} /$ $100 \mathrm{ml}$ ethidium bromide, using uncut DNA standards. 
Markers were scored using the following protocol: 50-100 ng template DNA was amplified by PCR using ISSR primer \#807 (AG8T) by one cycle of $94^{\circ} \mathrm{C}$ for $3 \mathrm{~min}$; 38 cycles of $94^{\circ} \mathrm{C}$ for $30 \mathrm{~s}, 38$ cycles of $50^{\circ} \mathrm{C}$ for $1 \mathrm{~min}, 38$ cycles of $72^{\circ} \mathrm{C}$ for $1 \mathrm{~min}$; one cycle of $72^{\circ} \mathrm{C}$ for $5 \mathrm{~min}$. PCR products were separated by electrophoresis on a $6 \%$ polyacrylamide mini-gel (Biorad MiniProtean II) for $1 \mathrm{~h}$ at $200 \mathrm{~V}$ and visualized by silver staining. Bands were checked for repeatability and against a negative control. Neutrality under the infinite alleles model was tested against a null distribution of 1000 randomized samples using the Ewens-Watterson test (Manly, 1985) as implemented in POPGENE v1.32 (Yeh et al, 1999).

\section{Genetic differentiation at ISSR loci}

Genetic differentiation $\left(F_{\text {st }}\right)$ between adjacent plots at ISSR loci was tested using the Bayesian approach designed for dominant markers by Holsinger et al (2002) as implemented in the program Hickory v1.0 (Holsinger and Lewis, 2003) with all options set to default values. The difference between the $F_{\text {st }}$ estimate for Plots 8 and 9-1 and that for Plots 11-2 and 12 was tested by comparison of their posterior distributions. Nei's genetic distance between all pairwise combinations of the six populations sampled (ie four plots plus two borders) were computed with POPGENE v1.32 using the option for dominant markers and 10000 bootstraps. Isolation-by-distance was tested by a Mantel test, as implemented in the program GenAlEx v5 (Peakall and Smouse, 2001). A simple Mantel test has a power of about 0.95 to detect a correlation of 0.5 for samples about the size of ours (Legendre, 2000).

\section{Results}

\section{Flowering phenology}

Based upon the $21 P$-values in Table 2, the FDR procedure set the critical value $\alpha=0.013$. There was no effect of Plot or Section on Anthoxanthum phenology on the transect crossing the $2-2 / 3$ boundary between the two control plots (Table 2, Figure 2a). Flowering phenology differed between Plots 8 and 9-1 and varied significantly between sections within plots (Table 2, Figure 2b). Flowering in Section 9 of Plot 8, near to the border with Plot 9-1, was significantly retarded by comparison with the two sections to either side of it: for planned comparisons of Section 8 vs Section 9, $t=2.099, P=0.035$; Section 9 vs Section 10, $t=3.366$, $P<0.0008$.

Flowering was significantly more advanced on Plot 9-1 than Plot 9-2 (Table 2), but there was no apparent border effect. There was significantly greater variation among Sections on Plot 11-2 than on adjacent Plot 12 (Table 2), but no inverse cline at the boundary. Significant variation in flowering stage was present between Sections of Plots $14-1 / 15$ and there was a Plot $\times$ Section interaction on Plots 16/15 (Table 2).

\section{Gene flow}

$F_{\text {st }}$ estimates for cpSSR loci were 0.0074 for Plots $8,9-1$ and 12 analysed as a group and 0.0258 for only the adjacent Plots 8 and 9-1. (Confidence limits for $F_{\text {st }}$ cannot be calculated by bootstrapping over loci in the $\mathrm{cp}$ genome because all loci form a single linkage group, which does not recombine.) The observed value of the Ewens-Watterson test statistic fell otside the $95 \%$

Table 2 A summary of ANOVA results for A. odoratum flowering phenology scores at peak flowering time in May

\begin{tabular}{|c|c|c|c|c|c|c|c|}
\hline Boundary & $p H$ difference & Years since split & Effect & $D f$ & $m s$ & $\mathrm{~F}$ & P-value \\
\hline \multirow[t]{3}{*}{$2-2 / 3$} & \multirow[t]{3}{*}{0} & \multirow[t]{3}{*}{137} & Plot & 1,4 & 710.4 & 0.93 & 0.390 \\
\hline & & & Section & 1,68 & 202.6 & 1.09 & 0.301 \\
\hline & & & Plot $\times$ Section & 1,68 & 23.8 & 0.13 & 0.722 \\
\hline \multirow[t]{3}{*}{$8 / 9-1$} & \multirow[t]{3}{*}{1.3} & \multirow[t]{3}{*}{$145^{\mathrm{a}}$} & Plot & 1,4 & 512.3 & 21.8 & 0.010 \\
\hline & & & Section & 1,71 & 832.7 & 7.34 & 0.008 \\
\hline & & & Plot $\times$ Section & 1,71 & 565.6 & 4.98 & 0.029 \\
\hline \multirow[t]{3}{*}{$9-1 / 9-2$} & \multirow[t]{3}{*}{0.3} & \multirow[t]{3}{*}{11} & Plot & 1,4 & 3072.48 & 21.72 & 0.010 \\
\hline & & & Section & 1,72 & 0.12 & 0 & 0.972 \\
\hline & & & Plot $\times$ Section & 1,72 & 454.12 & 4.61 & 0.035 \\
\hline \multirow[t]{3}{*}{$11-2 / 12$} & \multirow[t]{3}{*}{1.5} & \multirow[t]{3}{*}{118} & Plot & 1,4 & 2416.8 & 5.81 & 0.073 \\
\hline & & & Section & 1,52 & 3.6 & 0.01 & 0.913 \\
\hline & & & Plot $\times$ Section & 1,52 & 2911.4 & 9.77 & 0.003 \\
\hline \multirow[t]{3}{*}{$14-1 / 14-2$} & \multirow[t]{3}{*}{0.5} & \multirow[t]{3}{*}{11} & Plot & 1,4 & 324.3 & 73.53 & 0.074 \\
\hline & & & Section & 1,16 & 468.6 & 2.03 & 0.173 \\
\hline & & & Plot $\times$ Section & 1,16 & 753.2 & 3.26 & 0.090 \\
\hline \multirow[t]{3}{*}{$14-1 / 15$} & \multirow[t]{3}{*}{0.7} & \multirow[t]{3}{*}{$125^{\mathrm{a}}$} & Plot & 1,4 & 0 & 0 & 0.995 \\
\hline & & & Section & 1,72 & 728.5 & 6.48 & 0.013 \\
\hline & & & Plot $\times$ Section & 1,72 & 160.9 & 1.43 & 0.236 \\
\hline \multirow[t]{3}{*}{$16 / 15$} & \multirow[t]{3}{*}{0.4} & \multirow[t]{3}{*}{125} & Plot & 1,4 & 241.9 & 0.35 & 0.588 \\
\hline & & & Section & 1,68 & 802.2 & 2.33 & 0.132 \\
\hline & & & Plot $\times$ Section & 1,68 & 2568.9 & 7.45 & 0.008 \\
\hline
\end{tabular}

Statistically significant effects, adjusted for multiple comparisons $(\alpha=0.013)$ are highlighted in bold.

${ }^{a}$ Time since establishment of original plots. 

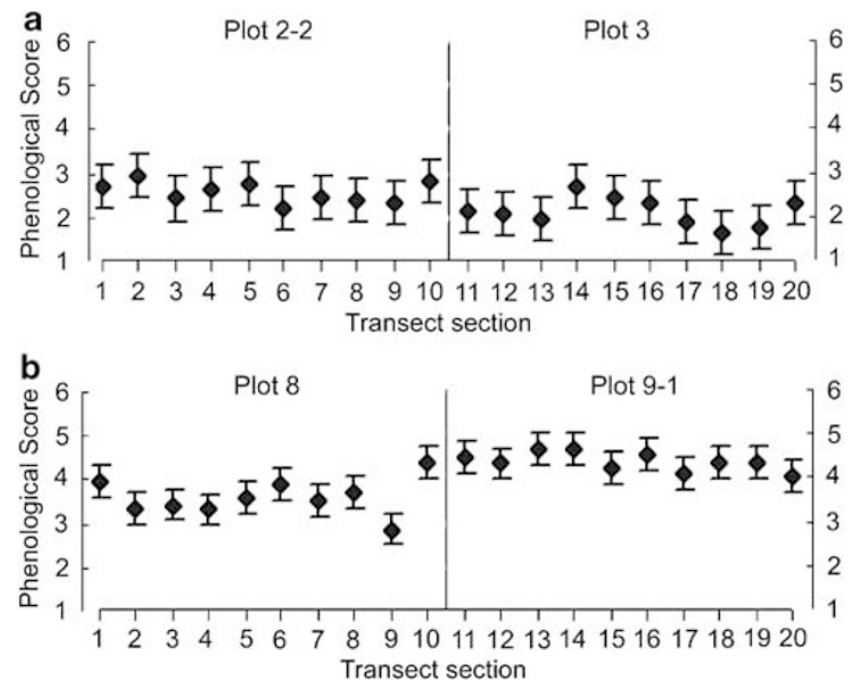

Figure 2 Mean phenological scores $( \pm S E)$ for A. odoratum flowering along transects crossing a boundary between (a) two control plots and (b) plots with a $\mathrm{pH}$ difference of 1.3 units.

confidence intervals of the expected value in six out of 54 cases ( $54=6$ populations $\times 9$ ISSR loci). For $\alpha=5 \%$, about three significant results might be expected to occur among 54 tests by chance alone. Therefore, there was no major departure in the spatial pattern of genetic differentiation from neutrality overall.

The ratio of gene flow via pollen and seeds across the 8/9-1 plot boundary calculated from $F_{\text {st }}$ estimates derived from the maternally inherited $\mathrm{cp}$ genome and the bi-parentally inherited $\mathrm{nr}$ genome was -1.344 . Estimates of this ratio that fall near unity lack precision (Ennos, 1994) and so this indicates that gene flow between Plots 8 and 9-1 via pollen was approximately equal to gene flow via seeds.

\section{Genetic differentiation at ISSR loci}

Pairwise physical distances between populations fell into two distinct groups, those $<5 \mathrm{~m}$ and those $>50 \mathrm{~m}$, representing the distances between adjacent populations on the one hand, and distances between populations in Plots 8/9-1 and those in Plots $11-2 / 12$ on the other. The mean pairwise genetic distance between populations $>50 \mathrm{~m}$ apart $(0.0203, \mathrm{SD} 0.0123, n=9)$ was $33 \%$ greater than that between adjacent populations $(0.0152, \mathrm{SD}$ $0.0157, n=6$ ), but this difference was not significant and there was no isolation-by-distance (Mantel test, $n=15, g=-1.095, P=0.130$ ).

Observed mean values of $\theta^{\mathrm{B}}$, equivalent to $F_{\mathrm{st}}$ under a random-effects model of population sampling were $\theta^{\mathrm{B}}=0.0387$ for Plots $8,9-1$ and their boundary and $\theta^{\mathrm{B}}=0.0280$ for Plots $11-2,12$ and their boundary. The lower bounds $(2.5 \%)$ of the minimum credible interval for these estimates (the Bayesian equivalent of the lower bound of $95 \%$ confidence limits in a frequentist test) were, respectively, 0.0021 and 0.0018 . Since neither lower bound was negative, both estimates of $\theta^{\mathrm{B}}$ were significantly greater than zero. Upper bounds $(97.5 \%)$ of the minimum credible interval were, respectively, 0.1063 and 0.0844 . The difference between the $F_{\mathrm{st}}$ estimate for Plots 8 and 9-1 and that for Plots 11-2 and 12 was tested by comparison of their posterior distributions. The minimum credible interval for their difference was negative $\left(\theta^{\mathrm{B}}=-0.01086\right.$, intervals $\left.=-0.08656,0.05301\right)$ and hence not significantly different from zero. Thus, $F_{\text {st }}$ estimates for the two sets of plots were of equivalent magnitude.

\section{Discussion}

Our results confirm the evidence gathered by Snaydon and Davies (1976), which suggested that natural selection has reinforced reproductive isolation between plots in the PGE. We found that over the course of more than a century, significant genetic differentiation has arisen between Plots 8 and 9-1 (spilt 145 years before sampling) and 11-2/12 (split for 118 years). A. odoratum is outcrossing and wind pollinated, so its population at Park Grass would have constituted a single panmictic unit before 1856 when the original meadow was subjected to divergent selection pressures exerted by the application of various fertilizers to different plots. Application of ammonium sulphate fertilizer to certain plots has greatly acidified the soil (Silvertown, 1980), producing a pH difference of one unit or more across certain boundaries (Table 2). At one such boundary, between Plots 8 and 9-1 (Figure 2b), we found an inverse cline in flowering time that confirms earlier results (Snaydon and Davies, 1976) on other PGE boundaries. The models of Caisse and Antonovics (1978) and Van Dijk and Bijlsma (1994) suggest that an inverse cline is a signature of reinforcement. The possibility that the inverse clines in the PGE might be boundary artefacts can now be discounted because a boundary of similar age between control Plots 2-2 and 3 (137 years old) showed no shift in flowering time in our study (Figure 2a).

The location of the inverse cline on Plot 8 is interesting because it lies between 0.2 and $0.4 \mathrm{~m}$ downwind of the boundary between Plots 8 and 9-1. The inverse cline in flowering time that Snaydon and Davies (1976) found between the limed subplots of Plots 8 and 9 lay on the boundary itself, but they noted that the maximum percentage difference between progeny raised from seed and parents, averaged across 11 traits including flowering time, did not occur on the boundary but was on Plot 8 , about $0.3 \mathrm{~m}$ from its boundary with Plot 9 . This falls precisely into the corresponding zone on the unlimed part of Plot 8 where we found flowering phenology to be shifted, creating an inverse cline. This is where one would expect to find selection on flowering time to be at its greatest, given that pollen travels downwind from Plots 9-1 to 8 .

The difference that Snaydon and Davies (1976) noted between progeny raised from seed without selection and tillers derived clonally from parents that had been subject to selection on Plot 8 suggests that, at the time they made the measurements, ovules located on plants $0.2-0.4 \mathrm{~m}$ into Plot 8 were being fertilized by pollen from Plot 9. This may have caused the trough of the inverse cline to move from the border into Plot 8 where we found it 33 years after Snaydon and Davies collected their samples (1968). Van Dijk and Bijlsma's (1994) model suggests that inverse clines should indeed move over time. However, we cannot be certain that the inverse cline moved because Snaydon and Davies (1976) studied populations on the border of the limed sections of Plots 8 
and 9, while we studied the border between the unlimed sections of those plots. However, given that an inverse cline was found by both studies, it seems unlikely that a difference in liming treatment would influence its initial location.

For reinforcement to evolve, flowering time must be heritable and there must be selection against hybrids (Butlin, 1987). By growing seed- and vegetatively derived plants through two generations of tillers in a common garden, Snaydon and Davies (1976) showed that flowering time differences are heritable in the broad sense. Flowering phenology can be correlated with plant size (eg Ollerton and Lack, 1998) and this might account for differences between Plots 9-1 and 9-2, which have different fertilizer treatments (Table 1), but it cannot account for the presence of an inverse cline within a plot. Plants transplanted across PGE plot boundaries experience a strong selective disadvantage compared to native genotypes (Davies and Snaydon, 1976). The low fitness of transplants is indirect, although firm evidence that hybrids between plants from adjoining plots with different fertilizer treatments would also have lower fitness than purely native genotypes.

Genetic differentiation at neutral (ISSR) loci between adjacent plots indicates that they are reproductively isolated from each other (Gavrilets, 2003) and may have been so for a century or more. The role of flowering time differences in this isolation is indicated by two lines of evidence. First, there was no significant isolation-bydistance that could account for reproductive isolation. Second, our estimate of the ratio of gene flow via pollen and seeds shows that flowering time differences have reduced effective pollen flow to an unprecedentedly low level for a wind-pollinated plant.

Owing to the much greater dispersability of pollen compared to most seeds, ratios reported in the literature are all positive (ie $F_{\mathrm{st} \text { (maternal) }} \gg F_{\mathrm{st}(\mathrm{nr})}$ ) and the median value of the ratio found in a survey of 93 studies by Petit et al (2005) was 17. So, our estimate of -1.344 is highly exceptional. Although very unusual, this result is completely consistent with the reinforcement of reproductive isolation between adjacent populations. $F_{\mathrm{st}}$ is normally calculated for populations separated by hundreds or thousands of metres, but Plots 8 and 9-1 are adjacent to one another and thus the dispersal barrier to seed flow (the denominator in the ratio) is very much lower than is usually the case, although the barrier to gene flow via pollen (the numerator) is not. $F_{\mathrm{st}}$ is proportional to realized gene flow, not merely the transport of seeds and pollen between populations, and thus there are two barriers to gene flow via any pollen that crosses the boundary between Plots 8 and 9-1. First, a pollen grain must be dispersed at the right time to reach a receptive stigma on the other plot and then any seedlings from seeds so sired must compete for survival with progeny sired by locally adapted plants. Although seeds that cross the boundary may have two nonadapted parents, their numbers are not subject to the barrier of premating isolation, which limits pollen flow.

McNeilly and Antonovics (1968) reported flowering time differences in A. odoratum and Agrostis capillaris (syn. A. tenuis) between populations of the same species on metal-contaminated sites and adjacent uncontaminated soils. Inverse clines were observed, suggesting reinforcement. Flowering-time shifts occurred at bound- aries on a variety of different substrates, making it unlikely that the similar shifts observed in different boundary populations were caused by soil conditions directly. Stam (1983) raised the possibility that in certain circumstances pollen flow between adjacent populations that are initially different in flowering time can lead to further divergence between them without any need for disruptive selection or reinforcement. This mechanism is driven by the nonrandom migration of genes for flowering time caused by the fact that matings across a population boundary can only take place between individuals with overlapping flowering time phenotypes. The Stam effect requires flowering times to be initially different between populations, heritable and sufficiently variable such that the flowering times of the earliest- and latest-flowering individuals do not overlap. This last condition may rule out the Stam effect at Park Grass because all flowering in A. odoratum is terminated when the hay is cut in mid-June and it therefore occupies a period of only 3-4 weeks. It is unlikely that individual plants have nonoverlapping flowering periods within this narrow window of time as required by Stam's model, although the possibility cannot be completely excluded using the data we have at present. More significantly, Stam's model (1983) did not produce inverse clines so its relevance to our observations at Park Grass is questionable.

Four of the boundaries we studied have separated plots with different fertilizer treatments for over a century, but we detected an inverse cline at only one of them. One such negative result affected the Plot 11-2/12 boundary where the $\mathrm{pH}$ difference (1.5 units) is even greater than that across the Plot 8/9-1 boundary $(1.3 \mathrm{pH}$ units) where the inverse cline was found, so the absence of appropriate selection pressures cannot explain the discrepancy. Significant genetic differentiation occurred across both boundaries, suggesting that we may have failed to pick up a real difference in flowering phenology at the 11-2/12 boundary. Another possibility is that some other means of reproductive isolation operates between Plots 11-2 and 12, as well as across other boundaries.

A fundamental distinction exists between two kinds of genetic mechanism underlying the evolution of reinforcement. In the so-called one-allele model reproductive isolation between diverging populations occurs through the spread of a single allele, which increases assortative mating (Felsenstein, 1981). For example, if an allele that caused increased selfing spread through two adjacent populations, it would increase reproductive isolation between them. Situations like this have been reported in grasses including $A$. odoratum (Antonovics, 1968). The second case is the so-called two-allele model where alternative alleles cause different mating preferences and assortative mating results from allele frequency differences between populations. The evolution of flowering time differences conforms to the two-allele model because different alleles must control whether flowering occurs early or late. In such a case, a divergence in allele frequencies between populations will increase the reproductive isolation between them. Whether the genetic basis of reinforcement is a one- or a two-allele mechanism affects how easily it can evolve in the presence of gene flow between populations (Kirkpatrick and Ravigne, 2002). The one-allele mechanism is immune to the countervailing effects of gene flow because it 
does not require genetic differentiation at the relevant locus to occur between populations. By contrast, gene flow is an obstacle to the evolution of reinforcement by the two-allele mechanism because this does depend upon genetic differentiation. Owing to this difference between the two mechanisms, cases of reinforcement conforming to the one-allele model are expected to be more common than cases of the two-allele model. Strong selection is required for reinforcement to evolve by the two-allele model, which may explain why we found no indication of reinforcement at the boundaries of plots with smaller $\mathrm{pH}$ differentials (Table 2). Evolution of reinforcement by either model must also overcome the constraint that linkage is required between the traits under direct selection (eg $\mathrm{pH}$ tolerance) and the isolating mechanism (eg flowering time). The PGE is a field laboratory of unique importance for the investigation of such evolutionary processes.

\section{Acknowledgements}

We are grateful to the trustees of the Lawes Trust for permission to sample the Park Grass Experiment. Support for this work was provided by the Open University, the Nuffield Foundation (to DM), NERC and IACR Rothamsted. We thank Alan Todd and Kevin McConway for statistical guidance, Zoe Hughes for field assistance and Spencer Barrett and his lab discussion group, Nick Barton, Deborah Charlesworth and Paul Poulton for comments on drafts of the manuscript.

\section{References}

Antonovics J (1968). Evolution in closely adjacent plant populations. V. Evolution of self-fertility. Heredity 23: 219238.

Barton NH (2000). Genetic hitchhiking. Philos Trans R Soc Lond Ser 355: 1553-1562.

Benjamini Y, Hochberg Y (1995). Controlling the false discovery rate - a practical and powerful approach to multiple testing. $J$ R Stat Soc Ser B 57: 289-300.

Butlin R (1987). Speciation by reinforcement. Trends Ecol Evol 2: 8-13.

Caisse M, Antonovics J (1978). Evolution of closely adjacent plant populations IX. Evolution of reproductive isolation in clinal populations. Heredity 40: 371-384.

Darwin C (1859). The Origin of Species by Means of Natural Selection, 1st edn. John Murray: London.

Davies MS, Snaydon RW (1973a). Physiological differences among populations of Anthoxanthum odoratum L. on the Park Grass Experiment, Rothamsted. I. Response to calcium. J Appl Ecol 10: 33-45.

Davies MS, Snaydon RW (1973b). Physiological differences among populations of Anthoxanthum odoratum L. on the Park Grass Experiment, Rothamsted. II. Response to aluminium. J Appl Ecol 10: 47-55.

Davies MS, Snaydon RW (1974). Physiological differences among populations of Anthoxanthum odoratum L. on the Park Grass Experiment, Rothamsted. III. Response to phosphate. J Appl Ecol 11: 699-707.

Davies MS, Snaydon RW (1976). Rapid population differentiation in a mosaic environment. III. Measures of selection pressures. Heredity 36: 59-66.

Ennos RA (1994). Estimating the relative rates of pollen and seed migration among plant populations. Heredity 72: 250-259.

Felsenstein J (1981). Skepticism towards Santa Rosalia, or why there are so few kinds of animals. Evolution 35: 124-138.
Gavrilets S (2003). Perspective: models of speciation: what have we learned in 40 years? Evolution 57: 2197-2215.

Hendry AP, Wenburg JK, Bentzen P, Volk EC, Quinn TP (2000). Rapid evolution of reproductive isolation in the wild: evidence from introduced salmon. Science 290: 516-518.

Higgie M, Chenoweth S, Blows MW (2000). Natural selection and the reinforcement of mate recognition. Science 290: 519-521.

Holsinger KE, Lewis PO (2003). Hickory: A Package for Analysis of Population Genetic Data, v1.0, 1.0 edn. Storrs: Connecticut.

Holsinger KE, Lewis PO, Dey DK (2002). A Bayesian approach to inferring population structure from dominant markers. Mol Ecol 11: 1157-1164.

Ishii T, McCouch SR (2000). Microsatellites and microsynteny in the chloroplast genomes of Oryza and eight other Gramineae species. Theor Appl Genet 100: 1257-1266.

Kirkpatrick M, Ravigne V (2002). Speciation by natural and sexual selection: models and experiments. Am Nat 159: S22-S35.

Kunin WE (1998). Biodiversity at the edge: a test of the importance of spatial 'mass effects' in the Rothamsted Park Grass experiments. Proc Natl Acad Sci USA 95: 207-212.

Legendre P (2000). Comparison of permutation methods for the partial correlation and partial Mantel tests. I Stat Comput Simul 67: 37-73.

Levin DA (2002). The Role of Chromosomal Change in Plant Evolution. Oxford University Press: Oxford.

Lewis PO, Zaykin D (2001). Genetic Data Analysis: Computer Program for the Analysis of Allelic Data. Version 1.0 (d16c). Free program distributed by the authors over the internet from http://lewis.eeb.uconn.edu/lewishome/software.html

Manly BFJ (1985). The Statistics of Natural Selection. Chapman \& Hall: London.

McNeilly T, Antonovics J (1968). Evolution in closely adjacent plant populations. IV. Barriers to gene flow. Heredity 23: 205-218.

Noor MAF (1999). Reinforcement and other consequences of sympatry. Heredity 83: 503-508.

Nosil P, Crespi BJ, Sandoval CP (2003). Reproductive isolation driven by the combined effects of ecological adaptation and reinforcement. Proc R Soc Lond Ser B 270: 1911-1918.

Ollerton J, Lack A (1998). Relationships between flowering phenology, plant size and reproductive success in Lotus corniculatus (Fabaceae). Plant Ecol 139: 35-47.

Peakall R, Smouse PE (2001). GenAlEx V5: Genetic Analysis in Excel. Population Genetic Software for Teaching and Research. Australian National University: Canberra, Australia.

Petit RJ, Duminil J, Fineschi S, Hampe A, Salvini D, Vendramin GG (2005). Comparative organization of chloroplast, mitochondrial and nuclear diversity in plant populations. Mol Ecol 14: 689-701.

Provan J, Biss PM, McMeel D, Mathews S (2004). Universal primers for the amplification of chloroplast microsatellites in grasses (Poaceae). Mol Ecol Notes 4: 262-264.

Saetre GP, Moum T, Bures S, Kral M, Adamjan M, Moreno J (1997). A sexually selected character displacement in flycatchers reinforces premating isolation. Nature 387 : 589-592.

Servedio MR (2004). The evolution of premating isolation: local adaptation and natural and sexual selection against hybrids. Evolution 58: 913-924.

Servedio MR, Noor MAF (2003). The role of reinforcement in speciation: theory and data. Annu Rev Ecol Evol Syst 34: 339-364.

Silvertown J, McConway KJ, Hughes Z, Biss P, Macnair M, Lutman P (2002). Ecological and genetic correlates of longterm population trends in the Park Grass Experiment. Am Nat 160: 409-420.

Silvertown JW (1980). The dynamics of a grassland ecosystem: botanical equilibrium in the Park Grass Experiment. J Appl Ecol 17: 491-504. 
Snaydon RW (1970). Rapid population differentiation in a mosaic environment. I. The response of Anthoxanthum odoratum to soils. Evolution 24: 257-269.

Snaydon RW, Davies MS (1972). Rapid population differentiation in a mosaic environment. II. Morphological variation in Anthoxanthum odoratum L. Evolution 26: 390-405.

Snaydon RW, Davies MS (1976). Rapid population differentiation in a mosaic environment. IV. Populations of Anthoxanthum odoratum L. at sharp boundaries. Heredity 36: 9-25.

Snaydon RW, Davies TM (1982). Rapid divergence of plant populations in response to recent changes in soil conditions. Evolution 36: 289-297.
Stam P (1983). The evolution of reproductive isolation in closely adjacent plant-populations through differential flowering time. Heredity 50: 105-118.

Van Dijk P, Bijlsma R (1994). Simulations of flowering time displacement between 2 cytotypes that form inviable hybrids. Heredity 72: 522-535.

Wallace AR (1889). Darwinism. Macmillan \& Co.: London.

Yeh FC, Yang R, Boyle T (1999) POPGENE ver. 1.31.

Zietkiewicz E, Rafalski A, Labuda D (1994). Genome fingerprinting by simple sequence repeat (ssr)-anchored polymerase chain-reaction amplification. Genomics $\mathbf{2 0}$ 176-183. 